\title{
Intravenous tranexamic acid is associated with safe reduced blood loss and transfusion rate in one-stage exchange for infected hip arthroplasty
}

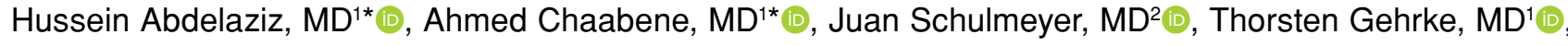

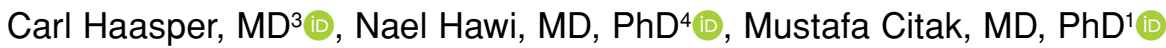 \\ 1Department of Orthopaedic Surgery, Helios ENDO-Klinik Hamburg, Hamburg, Germany \\ 'Department of Orthopaedic Surgery and Trauma, Hospital Barros Luco Trudeau, Gran Avenida Jose Miguel, Santiago, Chile \\ ${ }^{3}$ Department of Orthopaedic Surgery, AMEOS Klinikum Seepark, Geestland, Geestland, Germany \\ ${ }^{4}$ Department of Trauma Surgery, Hannover Medical School, Hannover, Germany
}

Compared to primary total hip arthroplasty (THA), a revision THA is more complex, involves extended exposures and soft-tissue dissection, and many of the affected patients have multiple morbidities. ${ }^{[1-3]}$ Therefore, revision THA is associated with longer surgical time, longer hospital stay, increased blood loss, blood transfusions, and higher complication and mortality rates. ${ }^{[4-7]}$ Regarding hip revision for periprosthetic joint infection (PJI), two-stage procedures have higher intraoperative blood loss and allogeneic blood transfusion rate compared to one-stage exchange. ${ }^{[8]}$

Received: July 01, 2020

Accepted: July 23, 2020

Published online: January 06, 2021

Correspondence: Mustafa Citak, MD. Department of Orthopaedic Surgery, Helios ENDO-Klinik Hamburg Holstenstrasse 2, 22767 Hamburg, Germany.

E-mail: mustafa.citak@helios-gesundheit.de

Doi: $10.5606 /$ ehc. 2021.77652

* Hussein Abdelaziz and Ahmed Chaabene have contributed equally in writing this manuscript

Citation: Abdelaziz H, Chaabene A, Schulmeyer J, Gehrke T, Haasper C, Hawi N, Citak M. Intravenous tranexamic acid is associated with safe reduced blood loss and transfusion rate in one-stage exchange for infected hip arthroplasty. Jt Dis Relat Surg 2021;32(1):17-21.

(C2021 All right reserved by the Turkish Joint Diseases Foundation

This is an open access article under the terms of the Creative Commons Attribution-NonCommercial License, which permits use, distribution and reproduction in any medium, provided the original work is properly cited and is not used for commercial purposes (http://creativecommons.org/licenses/by-nc/4.0/).

\section{ABSTRACT}

Objectives: This study aims to investigate if the use of intravenous (IV) tranexamic acid (TXA) during one-stage exchange for periprosthetic joint infection (PJI) of the hip that necessitates an extensive debridement is associated with decreased blood loss, if the rate of blood transfusion that may lead to side effects can be lowered with IV TXA, and if there is any difference regarding the occurrence of postoperative venous thromboembolism (VTE).

Patients and methods: We retrospectively reviewed patients who underwent one-stage exchange for PJI of the hip with perioperative IV administration of TXA ( $\mathrm{n}=163 ; 90$ males, 73 females; mean age $68 \pm 10.3$; range, 25 to 90 years) between January 2015 and December 2016 and compared them to another group ( $n=190$; 106 males, 84 females; mean age $71 \pm 10.1$; range, 39 to 92 years) who underwent one-stage exchange for PJI of the hip without perioperative IV administration of TXA between January 2006 and December 2012. Blood loss, transfusion rates, amount of transfused blood, and occurrence of VTE complications were observed.

Results: Mean blood loss of the TXA group was significantly lower than that of the non-TXA group $(2.4 \mathrm{~L}$ and $4.5 \mathrm{~L}$, respectively; $\mathrm{p}<0.001)$. Patients in non-TXA group experienced significantly higher rate of blood transfusion $(71.1 \%$ and $58.3 \%$, respectively; $\mathrm{p}=0.014$ ) and higher quantity of transfused packed red blood cells (3.2 and 1.9 units, respectively; $\mathrm{p}<0.001$ ). There was one patient with VTE complication in each group.

Conclusion: Even in the presence of infection, usage of IV TXA during one-stage exchange for PJI of the hip is associated with significantly lower blood loss and transfusion rates showing no higher risk of VTE events.

Keywords: Blood loss, blood transfusion, infected hip arthroplasty, intravenous, one-stage exchange, tranexamic acid.

Besides a meticulous surgical technique, antifibrinolytic medications such as tranexamic acid (TXA) can reduce blood loss in THA. ${ }^{[9,10]}$ Concerning the route of administration of TXA, i.e. intravenous (IV), 
oral, or intraarticular, all were effective in reducing the rates of blood loss in THA. ${ }^{[1]]}$ The routine use of IV TXA in primary total joint arthroplasty has been well established, as numerous randomized clinical trials and meta-analysis have demonstrated reduced perioperative blood loss and transfusion rates without a significant increase in venous thromboembolism (VTE) complication rates. ${ }^{[9-15]}$ In revision arthroplasty, there is increasing support of the use of TXA to reduce the perioperative blood loss, hence the need for allogeneic blood transfusions. ${ }^{[16-20]}$

Few studies have addressed the effectiveness of TXA in reducing blood loss and transfusion rates during PJI surgery. ${ }^{[20-22]}$ Goel et al. ${ }^{[21]}$ have shown a significant reduction in blood loss with the use of TXA in two-stage exchange procedures for PJI of the hip. The topical use of TXA was also associated with a significant decrease in blood transfusion rate for patients undergoing one- and two-stage exchange for PJI of the knee in a study by Waddell et al. ${ }^{[22]}$

However, to our best knowledge, there is no evidence-based recommendation regarding the IV use of TXA in one-stage exchange for PJI of the hip. Therefore, in this study, we aimed to investigate if the use of IV TXA during one-stage exchange for PJI of the hip that necessitates an extensive debridement is associated with decreased blood loss, if the rate of blood transfusion that may lead to side effects can be lowered with IV TXA, and if there is any difference regarding the occurrence of postoperative VTE.

\section{PATIENTS AND METHODS}

A retrospective analysis was performed to evaluate the efficacy of TXA usage on blood loss and transfusion rates in the setting of one-stage exchange for PJI of the hip. We have demonstrated lower blood loss and transfusion rates of patients undergoing one-stage exchange compared to the two-stage exchange of the hip in a previous study. ${ }^{[8]}$ In the current study, conducted at Helios ENDOKlinik in Hamburg, we included 190 patients of that study (106 males, 84 females; mean age $71 \pm 10.1$; range, 39 to 92 years) who underwent one-stage exchange of the hip between January 2006 and December 2012 without perioperative IV administration of TXA, and compared them to another group of 163 patients (90 males, 73 females; mean age 68 10.3 ; range, 25 to 90 years) who underwent one-stage exchange of the hip between January 2015 and December 2016 with perioperative IV administration of TXA. Patients with bleeding disorders or following surgeries within the last six months were excluded. Perioperative blood loss, postoperative transfusion rates, the amount of transfused blood, and the rate of postoperative occurrence of VTE events were compared between both patient groups. The study protocol was approved by the Local Ethical Committee in Hamburg. A written informed consent was obtained from each patient. The study was conducted in accordance with the principles of the Declaration of Helsinki.

The decision for one-stage exchange was established in all patients after identification of the causative pathogen through a preoperative aspiration. An experienced microbiologist was consulted for the systemic and topic antibiotic therapy. All procedures were performed in the lateral decubitus position using the posterior approach of the hip by well-experienced surgeons for the septic one-stage exchange. The infected prostheses and all of the hardware and cement material were removed. Following extensive soft tissue and bone debridement, as long as necessary, cemented hip prostheses were implanted. Postoperative intraarticular drainages for $48 \mathrm{~h}$ were utilized in patients of both groups. Patients were monitored at the intensive care unit for at least $24 \mathrm{~h}$.

Following the current guideline recommendations, patients under oral anticoagulant therapy had to stop their medications preoperatively. This included phenprocoumon (only four patients in the TXA group) at least one week and factor $\mathrm{Xa}$ inhibitors at least $48 \mathrm{~h}$ (only four patients in the TXA group) before the surgery. In all patients, postoperative VTE prophylaxis was carried out using a subcutaneous injection of low molecular weight heparin. Patients at higher risk of VTE complications received higher doses of low molecular weight heparin first at the fourth postoperative day. In the TXA group, TXA was administered only IV at a dose of $1 \mathrm{~g}$ immediately before the skin incision. In patients with intraoperative increased tendency to bleed $(28 / 163 ; 17 \%)$, an additional IV injection of $1 \mathrm{~g}$ TXA was performed after a time interval of $2 \mathrm{~h}$ from the first TXA dosage or at the end of the procedure. This was performed by the anesthesiologist upon the request of the surgeon following reviewing the patients' comorbidities to avoid increasing the risk of postoperative VTE such as in patients with a history of deep venous thrombosis (DVT) or pulmonary embolism (PE). No other hemostatic medications or blood supplements were administered.

Blood volume was determined according to the weight of the patient. Hemoglobin $(\mathrm{Hb})$ loss was calculated based on the weight of the patient, $\mathrm{Hb}$ difference between the initial preoperative $\mathrm{Hb}$ 
and the third postoperative day $\mathrm{Hb}$, and the amount of transfused blood. The effective blood loss was finally calculated using the following formula: Blood loss $(\mathrm{L})=\mathrm{Hb}$ loss $(\mathrm{g}) /$ initial $\mathrm{Hb}$ value $(\mathrm{g} / \mathrm{L})$.

Indications for postoperative blood transfusion were $\mathrm{Hb}$ level below $6 \mathrm{~g} / \mathrm{dL}$, and symptomatic or multimorbid patients with $\mathrm{Hb}$ levels 6 to $8 \mathrm{~g} / \mathrm{dL}$. Each transfusion unit contained $250 \mathrm{~mL}$ packed red blood cells. The number of transfused units was determined according to the $\mathrm{Hb}$ level, clinical status, and the patient's comorbidity. Autotransfusion systems were not used due to the existence of an infection.

\section{Statistical analysis}

The processing of the data and the statistical analyses were carried out using SAS 9.3 (SAS Institute Inc., Cary, NC, USA). Descriptive analysis was performed using number and mean for metric values. Absolute and relative frequencies describe the distribution of categorical data. Standard deviation (SD) and 95\% confidence interval (CI) were determined for main results. Shapiro-Wilk test was used for verification of the normal distribution of the data. Comparison between both groups was carried out with the t-test. Otherwise, the Mann-Whitney $\mathrm{U}$ test was utilized. Fisher exact test was applied to compare the distribution frequency of a categorical variable. All tests were two-tailed. A $p$ value of $<0.05$ was considered statistically significant.

\section{RESULTS}

Patients of the TXA group were younger (68 vs. 71 years, $p=0.027$ ) but had a higher mean Charlson Comorbidity Index (CCI) score $(2 \pm 2.0$ [range, 1 to 6] vs. $1 \pm 1.4$ [range, 1 to 6], $\mathrm{p}<0.001$ ) compared to the non-TXA group (Table I). The

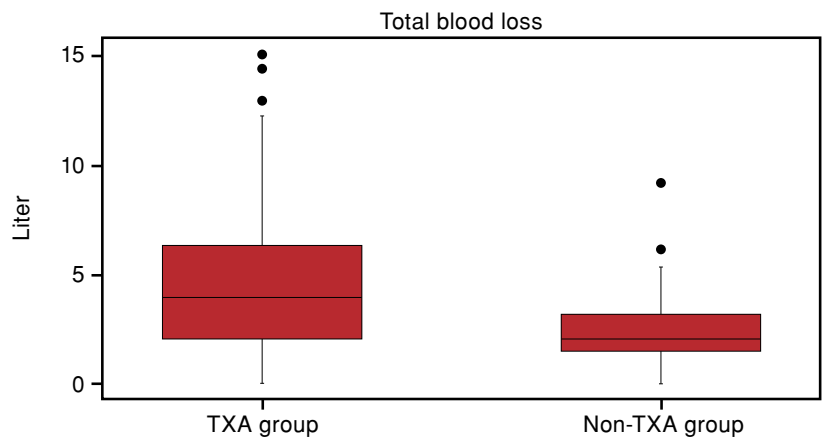

FIGURE 1. Box plot of calculated blood loss for both patient groups with and without administration of TXA, demonstrating a significant difference in favor of the TXA group ( $2.4 \mathrm{~L}$ and $4.5 \mathrm{~L}$, respectively; $\mathrm{p}<0.001$ ).

TXA: Tranexamic acid.

average preoperative $\mathrm{Hb}$ level was $12.27 \mathrm{mg} / \mathrm{L}$ in the TXA group and $12.79 \mathrm{mg} / \mathrm{L}$ in the non-TXA group $(\mathrm{p}=0.01)$. While the mean postoperative $\mathrm{Hb}$ was $9.14 \pm 1.27$ (range, 6.4 to 12.6 ) $\mathrm{mg} / \mathrm{L}$ on the first day and $9.26 \pm 1.29$ (range, 6.0 to 14.7 ) $\mathrm{mg} / \mathrm{L}$ on the third day for the TXA group, non-TXA group showed higher mean values $(9.9 \pm 1.1$ [range, 6.8 to 12.8 ] $\mathrm{mg} / \mathrm{L}$ and $10.18 \pm 1.21$ [range, 6.9 to 13.9 ] $\mathrm{mg} / \mathrm{L}$ on the first and third day, respectively; $\mathrm{p}=0.001$ ). The mean value of the last evaluated $\mathrm{Hb}$ level in the TXA group during the hospital stay was $10.3 \pm 1.17$ (range, 7.3 to 13.4$) \mathrm{g} / \mathrm{dL}$. The mean effective blood loss of patients in the TXA group was significantly lower than that of patients in the non-TXA group $(2.4 \pm 1.4 \mathrm{~L} ; 95 \% \mathrm{CI}: 2.1$ to 2.6$]$ and $4.5 \pm 3.0 \mathrm{~L} ; 95 \%$ CI: 4.0 to 4.9 ], respectively; $\mathrm{p}<0.001$ ) (Figure 1). The non-TXA group experienced a higher rate of postoperative blood transfusion compared to the TXA group $(71.1 \%$ and $58.3 \%$, respectively; $\mathrm{p}=0.014$ ), as well as a significantly higher quantity

\begin{tabular}{|c|c|c|c|c|c|c|c|}
\hline \multicolumn{8}{|c|}{$\begin{array}{l}\text { TABLE I } \\
\text { Demographic date of both patient groups }\end{array}$} \\
\hline \multirow[b]{2}{*}{ Variable } & \multicolumn{3}{|c|}{ TXA group } & \multicolumn{3}{|c|}{ Non-TXA group } & \multirow[b]{2}{*}{$p$} \\
\hline & $\mathrm{n}$ & $\%$ & Mean $\pm S D$ & $\mathrm{n}$ & $\%$ & Mean $\pm S D$ & \\
\hline Age (year) & & & $68 \pm 10.3$ & & & $71 \pm 10.1$ & 0.027 \\
\hline Sex & & & & & & & 0.915 \\
\hline Female & 73 & 45 & & 84 & 44 & & \\
\hline Male & 90 & 55 & & 106 & 56 & & \\
\hline Body mass index $\left(\mathrm{kg} / \mathrm{m}^{2}\right)$ & & & $29 \pm 5.8$ & & & $28 \pm 5.2$ & 0.131 \\
\hline Charlson comorbidity index & & & $2 \pm 2.0$ & & & $1 \pm 1.4$ & $<0.001$ \\
\hline Preoperative $\mathrm{Hb}(\mathrm{mg} / \mathrm{L})$ & & & $12.3 \pm 1.9$ & & & $12.8 \pm 1.9$ & 0.01 \\
\hline Postoperative $\mathrm{Hb}(\mathrm{mg} / \mathrm{L})$ on $1^{\text {st }}$ day & & & $9.1 \pm 1.3$ & & & $9.9 \pm 1.1$ & 0.001 \\
\hline Postoperative $\mathrm{Hb}(\mathrm{mg} / \mathrm{L})$ on $3^{\text {rd }}$ day & & & $9.3 \pm 1.3$ & & & $10.2 \pm 1.2$ & 0.001 \\
\hline
\end{tabular}


of transfused packed red blood cell units $(3.2 \pm 3.2$; 95\% CI: 2.7 to 3.6 ] and $1.9 \pm 2.4 ; 95 \%$ CI: 1.5 to 2.3 ] units, respectively; $\mathrm{p}<0.001)$. This is the relative risk, such as odds ratio, comparing between both groups.

Considering the rate of postoperative VTE, there was no difference between both groups, since one patient of DVT in the TXA group $(0.6 \%)$ and one patient of $\mathrm{PE}$ in the non-TXA group $(0.5 \%)$ were documented.

\section{DISCUSSION}

To our knowledge, there are no absolute contraindications to use IV TXA in the presence of infection. However, the literature is limited regarding its use in the setting of septic revision arthroplasty. Periprosthetic joint infection surgery is associated with an excessive blood loss due to the necessity of extensive debridement of the infective bone and tissue. In particular, during the one-stage exchange, an aggressive debridement is fundamental to eradicate the infection.

In the current study, we demonstrated a significant reduction in blood loss, the need for blood transfusion with a relative risk of 1.2 for transfusion, and the quantity of transfused blood in patients who received perioperative IV TXA during the one-stage exchange for PJI of the hip. The mean volume of the perioperative lost blood and the mean amount of blood needed to be transfused in non-TXA group were approximately double of that of the TXA group. Furthermore, patients in the TXA group had higher CCI scores; thus could benefit more from these results considering the risk of perioperative complications associated with massive blood loss, as well as allogeneic blood transfusion. Despite the higher comorbidity, the lower preoperative $\mathrm{Hb}$ level, and the longer duration of surgery of the TXA group compared to the non-TXA group, the blood loss and transfusion rate were lower than that of the non-TXA group. The one-stage approach technique did not change significantly over the years but the longer surgery time could be attributed to the increasing number of difficult and complicated cases referred to our arthroplasty center. Interestingly, the postoperative $\mathrm{Hb}$ levels were higher in the non-TXA group, which could be a result of the significant blood transfusion rate in that group, leading to an improvement and increase of the Hb levels.

Goel et al. ${ }^{[21]}$ reported on massive blood loss in patients undergoing two-stage exchange for PJI of the hip and found that TXA was associated with reduced blood loss. More recently, Hines et al. ${ }^{[2]}$ have demonstrated the effective use of IV TXA in reducing blood transfusion rate among patients who underwent revision hip arthroplasty, including 264 cases following two-stage exchange. In that extensive study cohort, there was no significant difference between patients with and without TXA in terms of VTE complications. In the current study, the perioperative usage of IV TXA also showed no risk of postoperative VTE complications.

Despite the relatively lower blood loss and transfusion rates in one-stage compared to two-stage exchange for PJI of the hip, ${ }^{[8]}$ the orthopedic surgeon should consider every tool, method, and technique to decrease blood loss during joint replacement surgery, hence reducing the need for perioperative blood transfusion, the risk of delayed ambulation, and postoperative hospital stay. Furthermore, patients receiving allogeneic blood transfusion are at increased risk of PJI. ${ }^{[23,24]}$

Recently, few studies have addressed the effect of TXA on infection rates; however, with controversial results. ${ }^{[25-27]}$ Tranexamic acid was associated with reduced postsurgical infection rate following cardiac surgery. ${ }^{[25]}$ On the other hand, the early use of TXA increased the risk of infection in severely trauma patients. ${ }^{[26]}$ Regarding the impact of TXA on PJI following primary total joint arthroplasty, Yazdi et al. ${ }^{[27]}$ demonstrated more recently an association between TXA and reduced infection rate. Likewise, Lacko et al. ${ }^{[28]}$ have more recently shown a lower cumulative revision rate for PJI following total knee arthroplasty.

Our study has some limitations. In addition to the possible selection bias associated with the retrospective design, a matching control group considering other variables is missing. Furthermore, despite the standardized surgical and postoperative management protocols for one-stage exchange at our arthroplasty center, different time periods of the performed one-stage exchange procedures between both groups might have associated with various confounders, such as different surgeons and management protocols for perioperative fluid resuscitation. Furthermore, longer follow-up to assess whether the administration of TXA has an impact on the reinfection rate would be interesting. Lastly, despite the relatively large sample size from a single institution, we believe that larger registry cohorts addressing the effect of TXA on the relatively rare VTE are still needed, particularly in such highly complicated surgeries. 
In conclusion, even in the presence of infected joints, the usage of IV TXA during the one-stage exchange for PJI of the hip is associated with significantly lower blood loss and transfusion rates showing no higher risk of VTE complications. Further prospective studies improving the matching criteria and avoiding the acknowledged limitations are warranted.

\section{Acknowledgement}

We thank Mrs. Silke Lange for performing the statistical analysis in this study.

\section{Declaration of conflicting interests}

The authors declared no conflicts of interest with respect to the authorship and/or publication of this article.

\section{Funding}

The authors received no financial support for the research and/or authorship of this article.

\section{REFERENCES}

1. Badarudeen S, Shu AC, Ong KL, Baykal D, Lau E, Malkani AL. Complications after revision total hip arthroplasty in the medicare population. J Arthroplasty 2017;32:1954-8.

2. Bozic KJ, Kurtz SM, Lau E, Ong K, Vail TP, Berry DJ. The epidemiology of revision total hip arthroplasty in the United States. J Bone Joint Surg [Am] 2009;91:128-33.

3. Cram P, Lu X, Kaboli PJ, Vaughan-Sarrazin MS, Cai X, Wolf $\mathrm{BR}$, et al. Clinical characteristics and outcomes of Medicare patients undergoing total hip arthroplasty, 1991-2008. JAMA 2011;305:1560-7.

4. Bozic KJ, Katz P, Cisternas M, Ono L, Ries MD, Showstack J. Hospital resource utilization for primary and revision total hip arthroplasty. J Bone Joint Surg [Am] 2005;87:570-6.

5. Schwartz BE, Piponov HI, Helder CW, Mayers WF, Gonzalez MH. Revision total hip arthroplasty in the United States: national trends and in-hospital outcomes. Int Orthop 2016;40:1793-802.

6. Bridgens JP, Evans CR, Dobson PM, Hamer AJ. Intraoperative red blood-cell salvage in revision hip surgery. A casematched study. J Bone Joint Surg [Am] 2007;89:270-5.

7. Bierbaum BE, Callaghan JJ, Galante JO, Rubash HE, Tooms RE, Welch RB. An analysis of blood management in patients having a total hip or knee arthroplasty. J Bone Joint Surg [Am] 1999;81:2-10.

8. Sharqzad AS, Cavalheiro C, Zahar A, Lausmann C, Gehrke $\mathrm{T}$, Kendoff D, et al. Blood loss and allogeneic transfusion for surgical treatment of periprosthetic joint infection: a comparison of one- vs. two-stage exchange total hip arthroplasty. Int Orthop 2019;43:2025-30.

9. Sezgin EA, Atik OŞ. Are we scientifically ready to adopt tranexamic acid as a routine in arthroplasty? Eklem Hastalik Cerrahisi 2019;30:338-9.

10. Yamasaki S, Masuhara K, Fuji T. Tranexamic acid reduces postoperative blood loss in cementless total hip arthroplasty. J Bone Joint Surg [Am] 2005;87:766-70.

11. Gianakos AL, Hurley ET, Haring RS, Yoon RS, Liporace FA. Reduction of Blood Loss by Tranexamic Acid Following Total Hip and Knee Arthroplasty: A Meta-Analysis. JBJS Rev 2018;6:e1.
12. Ho KM, Ismail $\mathrm{H}$. Use of intravenous tranexamic acid to reduce allogeneic blood transfusion in total hip and knee arthroplasty: a meta-analysis. Anaesth Intensive Care 2003;31:529-37.

13. Madsen RV, Nielsen CS, Kallemose T, Husted H, Troelsen A. Low risk of thromboembolic events after routine administration of tranexamic acid in hip and knee arthroplasty. J Arthroplasty 2017;32:1298-303.

14. Sukeik M, Alshryda S, Haddad FS, Mason JM. Systematic review and meta-analysis of the use of tranexamic acid in total hip replacement. J Bone Joint Surg [Br] 2011;93:39-46.

15. Mahomed NN, Barrett JA, Katz JN, Phillips CB, Losina E, Lew RA, et al. Rates and outcomes of primary and revision total hip replacement in the United States medicare population. J Bone Joint Surg [Am] 2003;85:27-32.

16. Park KJ, Couch CG, Edwards PK, Siegel ER, Mears SC, Barnes CL. Tranexamic Acid Reduces Blood Transfusions in Revision Total Hip Arthroplasty. J Arthroplasty 2016;31:2850-5.e1.

17. Kazi HA, Fountain JR, Thomas TG, Carroll FA. The effect of bolus administration of tranexamic acid in revision hip arthroplasty. Hip Int 2012;22:615-20.

18. Peck J, Kepecs DM, Mei B, Safir OA, Backstein D, Gross AE, et al. The Effect of Preoperative Administration of Intravenous Tranexamic Acid During Revision Hip Arthroplasty: A Retrospective Study. J Bone Joint Surg [Am] 2018;100:1509-16.

19. Reichel F, Peter C, Ewerbeck V, Egermann M. Reducing blood loss in revision total hip and knee arthroplasty: tranexamic acid is effective in aseptic revisions and in second-stage reimplantations for periprosthetic infection. Biomed Res Int 2018;2018:3891870.

20. Hines JT, Hernandez NM, Amundson AW, Pagnano MW, Sierra RJ, Abdel MP. Intravenous tranexamic acid safely and effectively reduces transfusion rates in revision total hip arthroplasty. Bone Joint J 2019;101-B(6_Supple_B):104-9.

21. Goel R, Buckley P, Sterbis E, Parvizi J. Patients with infected total hip arthroplasty undergoing 2-stage exchange arthroplasty experience massive blood loss. J Arthroplasty 2018;33:3547-50.

22. Waddell BS, Zahoor T, Meyer M, Ochsner L, Chimento G. Topical tranexamic acid use in knee periprosthetic joint infection is safe and effective. J Knee Surg 2016;29:423-9.

23. Cizmic Z, Feng JE, Huang R, Iorio R, Komnos G, Kunutsor SK, et al. Hip and knee section, prevention, host related: Proceedings of international consensus on orthopedic infections. J Arthroplasty 2019;34:S255-S270.

24. Akonjom M, Battenberg A, Beverland D, Choi JH, Fillingham Y, Gallagher N, et al. General assembly, prevention, blood conservation: proceedings of international consensus on orthopedic infections. J Arthroplasty 2019;34:S147-S155.

25. Draxler DF, Yep K, Hanafi G, Winton A, Daglas M, Ho H, et al. Tranexamic acid modulates the immune response and reduces postsurgical infection rates. Blood Adv 2019;3:1598-609.

26. Eidelson S, Karcutskie C, Mulder M, Meizoso J, Padiadpu A, Rattan R, et al. 1606: IS Tranexamic acid associated with infection in critically injured trauma patients? Critical Care Medicine 2018;46:787.

27. Yazdi H, Klement MR, Hammad M, Inoue D, Xu C, Goswami $\mathrm{K}$, et al. Tranexamic Acid Is Associated With Reduced Periprosthetic Joint Infection After Primary Total Joint Arthroplasty. J Arthroplasty 2020;35:840-4.

28. Lacko M, Jarčuška P, Schreierova D, Lacková A, Gharaibeh A. Tranexamic acid decreases the risk of revision for acute and delayed periprosthetic joint infection after total knee replacement. Jt Dis Relat Surg 2020;31:8-13. 